\title{
THE IMPACT OF THE COLOR SCHEMES IN THE INTERIOR DESIGN ON SOME GROUPS OF SPECIAL NEEDS CHILDREN (AUTISM, HYPERACTIVITY AND DISTRACTION)
}

Dalia Fouad Mahmoud ATTIA *

Department of Decoration and Interior Architecture, Higher Institute of Applied Arts, $6^{\text {th }}$ October, Egypt

\begin{abstract}
Colors are one of the elements of design vocabulary, and they play a fundamental role in the success or failure of any design, as they are responsible for the positive or negative impressions of the beholder. Modern psychology has highlighted that colors have different connotations and psychological effects, such as feeling cold or warm, feeling anxious or resting..etc, and other physiological effects on human neurons through the wavelengths of each color separately, and it is worth noting that the Arab world "Ibn Sina" (980-1038 AD) was the first to address color therapy in the book Canonmedicinia, which is considered the first reference in medicine worldwide, and he explained this by drawing a map of the effect of colors on body temperature and health condition. Color therapy was also known in medicine. Ancient Indian(Ayurveda), and it was one of the basic treatments with it, whereby the body was divided into seven sensory points, each of which is associated with a specific color. Often color schemes are used in interior design according to personal tastes, religious or environmental legacies, and since the role of the interior designer is to prepare the elements of the interior design in line with the function of the interior space on the one hand, and the users of these spaces on the other hand, the necessity to study the effect of different color schemes on The psychological and behavioral needs of children, especially some groups such as autism patients and hyperactivity and distraction patients, as they are among the diseases that have increased in the current century, and as they are neurological mental illnesses that require assistance in preparing and socially supporting a healthy interaction with the community.

Keywords

The Colour Schemes, Interior Design, Children, Autism, Hyperactivity, Distraction.
\end{abstract}

\section{Introduction}

The main objective of the interior design is to create a suitable environment (functionally and aesthetically) to carry out a specific activity, which requires studying the behavior of users of the interior space on a number of basic elements, which are the horizontal and vertical determinants of the space, furniture, ventilation, lighting, materials and colors. Hence the importance of colors as one of the elements that have a direct impact on the success of the interior design, and an indirect effect through the inherent power of colors that change the sense of space in terms of narrow, breadth, height, visual illusion ... etc., and also for the psychological effects on mood And behavior.

This research focuses on the therapeutic effect of different colors in terms of helping to modify the behavior of children with autism spectrum or children with ADHD, in order to increase the prevalence of these diseases in recent times, and to start the international interest in them, and the American Council for Children with Special Needs is considered The Council for Exceptional Children, known as (CEC), is an institution that has a global impact on how to deal

* Corresponding author: info@appliedarts.edu.eg 
with children with special needs in general. It has adopted a number of standards to deal with these groups of children and methods of treating or correcting them. These standards include attention to the spaces surrounding them, their components and the extent Its effect on their general behavior.

And it has trends towards color therapy, whose theories are based on the psychological and physiological effects of colors on the human body as a result of the different wavelengths of each color separately.

As it usually does not take into account these different effects of colors used in interior design elements and furniture on this category of children. Therefore, the research is interested in providing an information base for interior designers on the psychological and physiological effects of colors on these groups of children, as a contribution to modifying their behavior through positive stimuli for colors.

\section{The problem:}

Lies in the following questions:

- Can the use of specific color schemes for interior design contribute to some internal spaces for children with autism and hyperactivity and distractibility patients in improving or modifying their behavioral and psychological patterns?

How can the positive effects of different color schemes be used in the interior design in improving or modifying some behavioral or psychological patterns of children with autism and hyperactivity and distractibility patients?

\section{Research hypothesis:}

The research assumes that the colors of the internal spaces can help in the psychological and behavioral modification of children with autism and hyperactivity and attention deficit hyperactivity disorder.

\section{Objectives:}

Learn about the different color schemes in interior design.

-Study and evaluation of the psychological and behavioral effects of using different color schemes in the internal spaces of children with autism, hyperactivity and distractibility.

\section{Importance of the research}

- Shedding light on the importance of color schemes in interior design as one of the means that can be used for psychological and behavioral modification of children with autism, hyperactivity and distractibility.

- Directing the attention of interior designers to the need to pay attention to the needs and requirements of the internal living, educational and recreational environment for children with 
autism, hyperactivity and distraction, which differ from the needs of their healthy peers, in response to the Egyptian state's interest in the rights of people with special needs, on which Law No. 10 of 2018 was issued.

\section{Research methodology:}

The research follows the descriptive and analytical approach through the following axes:

First: you know the color and strategies for choosing color schemes in interior design.

Second: the behavioral characteristics of children with autism and ADHD.

Third: References Choose colors for the internal spaces of children (patients with autism and patients with ADHD).

Fourth: Results and Recommendations.

\section{Results:}

- The state has begun to pay attention to the requirements of people with special needs who have mobility, auditory or visual disabilities in public facilities, by setting special codes for construction, and neglecting patients with neurological disabilities such as the autism spectrum and patients with hyperactivity and attention distraction, due to the lack of adequate studies of their needs and requirements within the internal environments Different.

- Colors can be used in the internal spaces of children, to help modify the psychological and behavioral patterns of children with autism and patients with ADHD.

- Lack of interest in color schemes and their disparate effects on children with autism and hyperactivity and distraction in the internal spaces for dealing with them, such as clinics, hospitals, educational or recreational spaces.

\section{Recommendations:}

- Making adjustments in color schemes for some internal spaces of public establishments concerned with dealing with children with autism and ADHD, which positively affect their psychological and behavioral patterns, especially since they are simple adjustments that do not require effort nor great cost.

- Paying attention to everything that pertains to children with special needs and researching the amendment of internal spaces to suit them and to help them integrate into society in order to support the Egyptian state for people with various disabilities and integrate them into society after the issuance of Law No. 10 of 1018 and its executive regulations.

\section{References}

1. Al-Khuristani, Rabi`. Eilabouni, Michel. Architectural display and color. Lebanon: Gabes Publishing House, 1998.

2. Badr, Siham Muhammad. Trends of educational thought in the field of childhood. Cairo: 
The Anglo-Egyptian Library, 2002.

3. Perrin, Weber, translation by Mukhtar, Safiyyah. Colors and human responses. Cairo: Hindawi Publishing Corporation, 2017

4. Jumah, Hussein Muhammad. Colors from psychology to decor. Second Edition. Cairo: Association for the Preservation of Real Estate Wealth and Architectural Development, Engineering Studies and Consultation Office, 2006

5. Hammouda, Yahya. Color theory. Cairo: Dar Al Ma'aref, 1981

6. Khalaf, Nameer Qasim. A. Interior design. Iraq: University of Diyala, 2005

7. Rajeh, Ahmed Ezzat. The Origins of Psychology. Beirut: Dar Al-Alam, 1988

8. Fathy, Magdy. The effectiveness of a training program to develop communication skills on some behavioral manifestations of autistic children. First edition. Cairo: Dar Al-Arabi Publishing, 2002

9. Farraj, Othman Labib. Childhood intellectual disabilities (definition - classification symptoms - diagnosis - causes - therapeutic intervention). First edition. Cairo: Arab Council for Childhood and Development, 2002

10. Qabbani Rasha. Encyclopedia of Child Health. Lebanon: House of Knowledge, 2017

11. A.J.Paron, Wildes. Interior design for Autism (from CHILDHOOD to ADOLESCENCE). USA: Wiley E-book Design shorts, 2005.

12. Gimbel,Theo. Healing Through Color. USA: C W Daniel Co Ltd, 1980

13. Mostafa, Magda. An Architecture for Autism. Research. Journal of Architecture research. Volume 2 Issue 1.2008.

14. Roy S. Berns. Principles of color Technology. Third edition. USA: Published by John Wiley \& Sons Inc., 2000

15. https://www.almanny.com>ar-ar 21/12/2019

16. https://pin.it/gMaVmQZ 2/1/2020

17. https://pin.it/cHcYHuJ 2/ 1/2020

18. www.interyourah.com $5 / 1 / 2020$

19. Mona Ezzat Hamid ABDEL AZIZ, Rasha Hassan Hosni SALEM, THE AESTHETIC AND PLASTIC CAPABILITIES OF THE ART OF MACRAMÉ AND UTILIZING IT IN DESIGN AND IMPLEMENTATION WOMEN'S CLOTHING SUPPLEMENT, International Journal of Design and Fashion Studies, Vol. 2, No. 2, 2019, pp. 10-19. 